\title{
Community Design Circles: Co-designing Justice and Wellbeing in Family-Community-Research Partnerships
}

\author{
Ann M. Ishimaru \\ Aditi Rajendran \\ Charlene Montaño Nolan \\ University of Washington \\ USA \\ Megan Bang \\ Northwestern University \\ USA
}

\begin{abstract}
Researchers and practitioners of family engagement have long called for a move beyond conventional deficit-based family-school partnerships. In response, a burgeoning movement in the field has sought to identify and enact new forms of collaboration with nondominant families and communities, in terms of both change-making and the process of research itself. In this article, we bridge the fields of family engagement and design-based research to conceptualize and illustrate a solidarity-driven process of partnership undertaken with families and communities of color, educators, and other researchers toward community-defined wellbeing and education justice. We offer community design circles as a methodological evolution aimed at reclaiming the central agentic role of families and communities of color in transforming educational research and practice. Vignettes from a national-level participatorydesign research project called the Family Leadership Design Collaborative illustrate three codesign dimensions: 1) building from and with families' and communities' definitions of wellbeing and justice; 2) disrupting normative, asymmetrical dynamics; and 3) building capacity for social dreaming and changemaking.
\end{abstract}

Keywords: participatory design methodologies, educational justice, community wellbeing, partnerships, racial equity, solidarities. 


\section{Introduction}

In recent decades, a number of researchers, policy-makers, and practitioners have looked to nondominant 1 families and communities as key "partners" to eliminate education inequities and disparities in student learning, promote student success, and contribute to school improvement efforts (Bolívar \& Chrispeels, 2011; Bryk, Sebring, Allensworth, Easton, \& Luppescu, 2010; Mapp \& Kuttner, 2013). In addition, recent scholarship has begun to recognize research-practice partnerships (see Coburn \& Penuel, 2016) and community-engaged scholarship (see Warren, Calderón, Kupscznk, Squires \& Su, 2018) as forms of educational research that seek to develop findings with direct relevance to change efforts on the ground in schools and communities. Across these two dynamics, a burgeoning movement in the field seeks to theorize and enact new forms of collaboration with nondominant families and communities, in terms of both change-making practice and the process of research itself. In this article, we conceptualize and illustrate a solidarity-driven process of partnership we undertook with families, communities, educators, and other researchers toward community-defined wellbeing and education justice. In particular, we offer community design circles as a methodological evolution aimed at reclaiming the central agentic role of families and communities of color in transforming educational research and practice.

\section{Beyond Conventional Family-School Partnerships}

A robust body of literature highlights the powerful contributions of nondominant families in education, even amidst racialized and asymmetrical power dynamics that constrain family-school relations (e.g., Baquedano-López, Alexander, \& Hernández, 2013; Kirmaci, Allexsaht-Snider, \& Buxton, 2018; Olivos, 2006). Through their histories, lived experiences, and cultural and linguistic practices, nondominant families can contribute valuable "funds of knowledge" and critical expertise to the work of teaching and learning toward more equitable outcomes (Ishimaru, Barajas-López, \& Bang, 2015; Moll, Amanti, Neff, \& Gonzalez, 1992; Valdés, 1996). Further, literature in community organizing for education reform underscores the potential of families to hold institutions accountable through exerting their collective power and to address education justice as part of broader social, political, and economic movements such as health, housing, immigration, racial, environmental, and criminal justice (Anyon, 2009; Mediratta, Shah, McAlister, 2009; Shirley, 1997; Warren, Mapp, \& Community Organizing and School Reform Project, 2011).

Yet, even when we recognize the importance and equity-imperative of partnerships with families, our processes and practices of partnering often continue to operate within white, normative, and asymmetric power paradigms (Auerbach, 2012; Ishimaru \& Takahashi, 2017). Conventional partnerships with nondominant families in schools tend to reinforce dominant norms, assumptions, and expectations that can constrain meaningful collaboration with nondominant communities and even reinforce education inequities (Bang, Montaño Nolan, \& McDaid-Morgan, 2018; Ishimaru, 2014; Lawrence-Lightfoot, 2003; Jiménez-Castellanos \& Gonzalez, 2012). The "taken-for-granted" norms, practices, and expectations of schools are often unspoken yet undergird behaviors and interactions between families and schools (Pushor, 2010; 2012). Moreover, these taken-for-granted norms are racialized. Ishimaru and Takahashi (2017) highlight how the dominant script made available to families is one of deference to educators as passive supporters of the school's agenda and illuminate how these scripts are racialized in the ways that (white) educators perceive and interact with families of color. Racialized scripts that designate families of color as "hard-to-reach," "problem parents," or "uninvolved" reflect 
institutional attributions aligned to a dominant norm of whiteness in school engagement practices, operationalized through activities like attending Parent-Teacher Association (PTA) meetings, fundraising, and monitoring homework completion (Lareau \& Horvat, 1999). These assimilative conceptions of "parent engagement" are not lost on families of color; they can, in turn, negatively shape the disengagement of families from educators and schools (Doucet, 2011; Dyrness, 2009; Valenzuela, 1999).

A growing body of work has begun to call for a move beyond the widely-used Epstein $(1992,1995)$ typology of parent involvement as the dominant framework through which schools seek to engage families (Auerbach, 2007; Fernández \& López, 2017; Schutz, 2006). While the framework played an important role in helping educators to attend to the importance of parents in schools, its use in practice tends to count only narrowly-defined, white engagement practices that promote the school's agenda and do not attend to the dynamics of race, class, immigration and other intersections that shape how families engage in learning with their children (Baquedano-López et al., 2013; Wilson, 2009). In this way, the conventional framework for socalled partnerships between schools and families serves to reinforce the dominant cultural norms and power asymmetries (Auerbach, 2012). As Warren et al. (2009) contend, "partnership" becomes a code word for families' passive support of the agenda, curriculum, and mission of the school.

Further, although scholars and educators may recognize that families' cultural practices and expertise can be valuable resources for learning, opportunities for families to make key decisions about their children's learning remain rare and often disingenuous (Anderson, 1998; Bang, Marin, \& Medin, 2018; Ishimaru, 2017). For example, Madden, Higgins, and Korteweg (2013) describe how the Canadian school in their study attempted to tap into familial funds of knowledge to engage Indigenous families through cultural signage, friendly office staff, and a drumming group after school. However, Indigenous families reported continued racism and token ways that teachers and administrators tried to incorporate Indigenous knowledges and cultural practices into classroom curriculum without collaboration or consultation with Indigenous peoples. Their study illuminates how teachers are often tasked with finding and extracting what they believe to be relevant cultural knowledge and adapting lessons plans to be more "culturally relevant." Thus, even promising school-community partnership practices (e.g., home visits, listening sessions, engaging funds of knowledge, and other forums for family input) can reify normative dynamics when only educators - and not families - make decisions that are consequential to teaching and learning.

\section{Family-Community-Research Partnerships}

These inequitable partnership dynamics are not exclusive to school-community partnerships; rather, they reflect broader racialized narratives and historical dynamics that inevitably extend to and shape our research practices and processes. As Ishimaru and Takahashi (2017) contend, "educational researchers may be no less influenced by the 'commonsense' institutional scripts that relegate families, particularly from nondominant communities, as the object of study - rather than key subjects with whom to design, implement, and build new knowledge and forms of activity" (p. 357). As a result, research-community partnerships may reinforce asymmetrical power relations, re-instantiate whiteness as a dominant paradigm, or leave families out of changemaking (Philip, Bang, \& Jackson, 2018). For example, focus groups are commonly employed in research-practice partnerships to surface issues, tensions, or traumas within communities in order for others, often not from within the community, to better understand the issues or context from participant perspectives. This method may amplify the 
voices and experiences of nondominant families and provide critical lenses for scholars to envision change; however, it is not always clear how families and communities who participate in this research are positioned as agentic changemakers.

We build from long-standing approaches that seek to leverage research to support change-making efforts in schools and communities, particularly organizing led by families and communities of color in holding educational and other institutions accountable for equitable resources, policies, and practices (Fine et al., 2003; Mediratta, Shah, \& McAlister, 2009; Oakes \& Rogers, 2006). Such community-engaged scholarship (CES) embraces principles of reciprocity and mutual expertise within a broader aim of producing findings that are "directly relevant to social change agendas" (Warren, Park, \& Tieken, 2016, p. 234). Many communityengaged scholars take up conventional methods, such as focus groups, interviews, or participant observations in ways that seek to be responsive to communities and consistent with communityengaged principles (Warren et al., 2018). In participatory and other action research, participants are engaged in every step of the process from design and data collection to analyses and writing (Cammarota \& Fine, 2008; Fox et al., 2010; Mirra, Filipiak, \& Garcia, 2015).

Other CES researchers might share findings with participants and work to address their feedback in refining their understandings. There has been less focus, however, on methods that explicitly work to disrupt normative power relations and decision-making within the research process itself. That is, the roles of researcher and researched remain relatively well delineated, with research expertise presumed to reside with formal scholars, whereas lived experience and expertise on inequities reside solely with research participants. Although CES often aims to exchange these forms of expertise through the research, there has been little explicit focus on how our research methods might evolve to enable such powered boundaries to become more permeable in order to also engage the familial and community expertise of researchers as well as the cultural practices and knowledge about learning and inquiry that families and communities often bring. Beyond shifting our stances in taking up conventional research methods, we posit that methodological innovations might begin to expand collective expertise and enact new forms of activity in the research process itself. That is, we seek to position research not simply as an outcome to leverage in an existing power paradigm, but a process of change-making that opens new transformative solutions and actions.

Outside of the field of family engagement ${ }^{2}$, there have been efforts in critical design research to (re)center family expertise and cultivate partnerships that sustain collective changemaking as a core principle of the research process (e.g., Bang \& Vossoughi, 2016). For example, Philip et al. (2018) challenge researchers to consider 1) our process of engaging families and communities; 2) for what purposes we are researching on or with families and communities; 3) who will benefit from the process and outcomes of our research; and 4) with whom we collaborate in each stage of our research. This is particularly consequential for nondominant communities who have had research aimed at them or for them (e.g., Gutiérrez, R., 2008), but rarely with them as designers and enactors of their own forms of justice (e.g., Philip et al., 2018). Given the atrocious historical legacy of research on communities, particularly communities of color, that has legitimized and justified the dehumanization of peoples (e.g., Tuskegee studies) and contributed to cultural and linguistic genocide (e.g., monolingualism policy), we build upon and extend the work of researchers who hold that our research processes are accountable not only to the narratives of communities that we put in the world, but also to actively cultivating justice and wellness in our work and the lives of our communities (see Booker, Vossoughi, \& Hooper, 2014; Gutiérrez \& Jurow, 2016; Vakil, McKinney de Royston, 
Nasir, \& Kirshner, 2016).

Leveraging the critical work from family engagement and design based research, our aim in this piece is to offer methodological approaches that envision collective agency and systemic transformation beginning with families' hopes and dreams, while also accounting for the hereand-now challenges facing many communities. Specifically, we offer solidarity-driven co-design as a methodological innovation that emerged from our participatory design research with nondominant families and communities as part of the Family Leadership Design Collaborative (described below). We begin with a brief summary of our methodological foundations, then concretize these co-design concepts with vignettes from a participatory design research project. Through these examples, we highlight three dimensions of this solidarity-driven process of research and practice.

\section{Methodological Foundations of Participatory Design Research}

Participatory design research (PDR) is an iterative methodology that seeks to advance theories of human learning alongside new sets of relations, practices, and tools to support social justice and change-making (Bang \& Vossoughi, 2016). Participatory design research is informed by and builds upon cultural historical activity theory and the change laboratories that have emerged from it (Cole, 1998; Engeström, 2004), as well as design research (Bell, 2004; Design Based Research Collaborative, 2003) and other critical, participatory, and community engaged scholarship such as decolonizing methodologies (Patel, 2015; Smith, 2013), critical race theories (Brayboy, 2005; Ladson-Billings \& Tate, 1995), participatory action research (Cammarota \& Fine, 2008; Erickson, 1994); social design experiments (Gutiérrez, K. D., 2008), communitybased design experiments (Bang, Medin, Washinawatok, \& Chapman, 2010); and community organizing and social movements (Anyon, 2009; Warren et al., 2011).

Aligned with this broader movement toward justice-oriented education research, PDR attends to how we build solidarity with communities and within the research process. Specifically, PDR follows in the tradition of other design-based methodologies to deliberately pose "how can" questions in order to generate knowledge and solutions toward new possibilities. Compared, to "how do" questions (understandings of the ways things currently are), "how can" questions aim research towards the future and the way things could be. Similar to other critical methodologies, PDR keeps in view systems that are in need of repair, as opposed to repairing deficits within individuals (Bertrand et al., 2017; Booker \& Goldman, 2016).

All research partnerships, but especially those that seek to center marginalized individuals, families, and communities, are steeped with the legacies of accumulated power, historical inequities, and unjust relationships. As such, careful and ongoing attention must be paid to relational dynamics in order to equitably engage in partnership. As Vakil et al. (2016) urge us, "making visible this relational work will allow the research community to better understand the sets of skills and competencies required to engage in theoretically rich, ethically sound, and hopefully equitable design research" (p. 196). Like many of the sibling methodologies mentioned above, PDR attends to the ways normative power is re-inscribed in the roles and relations between researchers and "the researched." As Bang and Vossoughi (2016) state, "from within a PDR paradigm, the domain of the 'researched' in a given project is expanded to include the relational, pedagogical, and design-based activity of researchers themselves, creating potentially new openings for reciprocity, accountability, and the de-settling of normative hierarchies of power" (p. 174). In this way, roles (e.g., researcher, parent, educators) are porous categories that create space for expansive and multidimensional identities. 
Finally, PDR has at its center an understanding of how the past has - and continues toshape the present and how it constrains or makes possible futures, including how historicallyrooted dynamics impact processes of partnership. Attending to critical historicity in this way means making visible the political and theoretical histories of a particular project, including our personal histories, to unearth the values, goals, and outcomes in order to disrupt inequitable partnerships and re-imagine transformative possibilities (Bang \& Vossoughi, 2016; Vakil et al., 2016). This understanding of historicity includes the researchers' social locations and histories that, if unexamined, may "conceal racialized, classed, gendered, colonizing power dynamics, often under the guise of neutrality" (Bang \& Vossoughi, 2016, p. 177).

Co-design is a critical practice of participatory design research and a key way that we have engaged in building solidarity with communities, educators, and researchers in our project. Through solidarity-driven co-design we aimed to enact the research principles of participatory design research, such as addressing power dynamics, critical historicity, and relationality with explicit attention to cultivating solidarity. In the next section we outline solidarity-driven codesign, then explain how we enacted this practice within our project.

\section{Co-design as a Participatory Method}

Co-design is a method of education research that brings together diverse stakeholders in order to collectively and iteratively identify issues or problems of practice and design solutions. Drawing from the critical and decolonizing scholarship of PDR described above, we enacted codesign as a solidarity-driven process of partnership to cultivate social dreaming (Espinoza, 2008) - that is, the collective imagining of future possibilities — and changemaking. While many forms of co-design seek to build collaboration between diverse stakeholders, they are not always explicit about how they attend to historically accumulated forms of power and forms of decisionmaking that operate in how people participate in the co-design process.

There are, broadly, 4 iterative stages of a solidarity-driven co-design process: a) relationship building \& theorizing; b) designing/developing tools to support new relationships and theories of change; c) implementing our theories and practices; and d) analyzing and reflecting on our process for continued learning and innovation. Figure 1 is a representation of a sample iterative design process, with any given process having more or fewer macro/micro cycles depending on the length of the project (adapted from Gravemeijer \& Cobb, 2006). These macro-stages or macrocycles may have minicycles of theorizing, designing, enacting, and reflecting embedded. These stages are not meant to be linear, rather they offer a way of designing that allows for iteration and collective sensemaking with careful attention paid to how power, values, and histories are being instantiated. Design research has largely focused on developing tools and practices that support expansive forms of learning and identity development but has attended less to the relational dynamics and value-laden decisions undergirding the design process (Bang et al., 2016; Zavala, 2016). Contributing to the field of design research, we specifically attend to this first stage: relationship building and theorizing. That is, we carefully look at how we might design for new forms of partnership to occur and heterogeneous definitions of wellbeing and justice to proliferate. By partnerships, we mean not only partnerships between schools and communities, but also with researchers. 


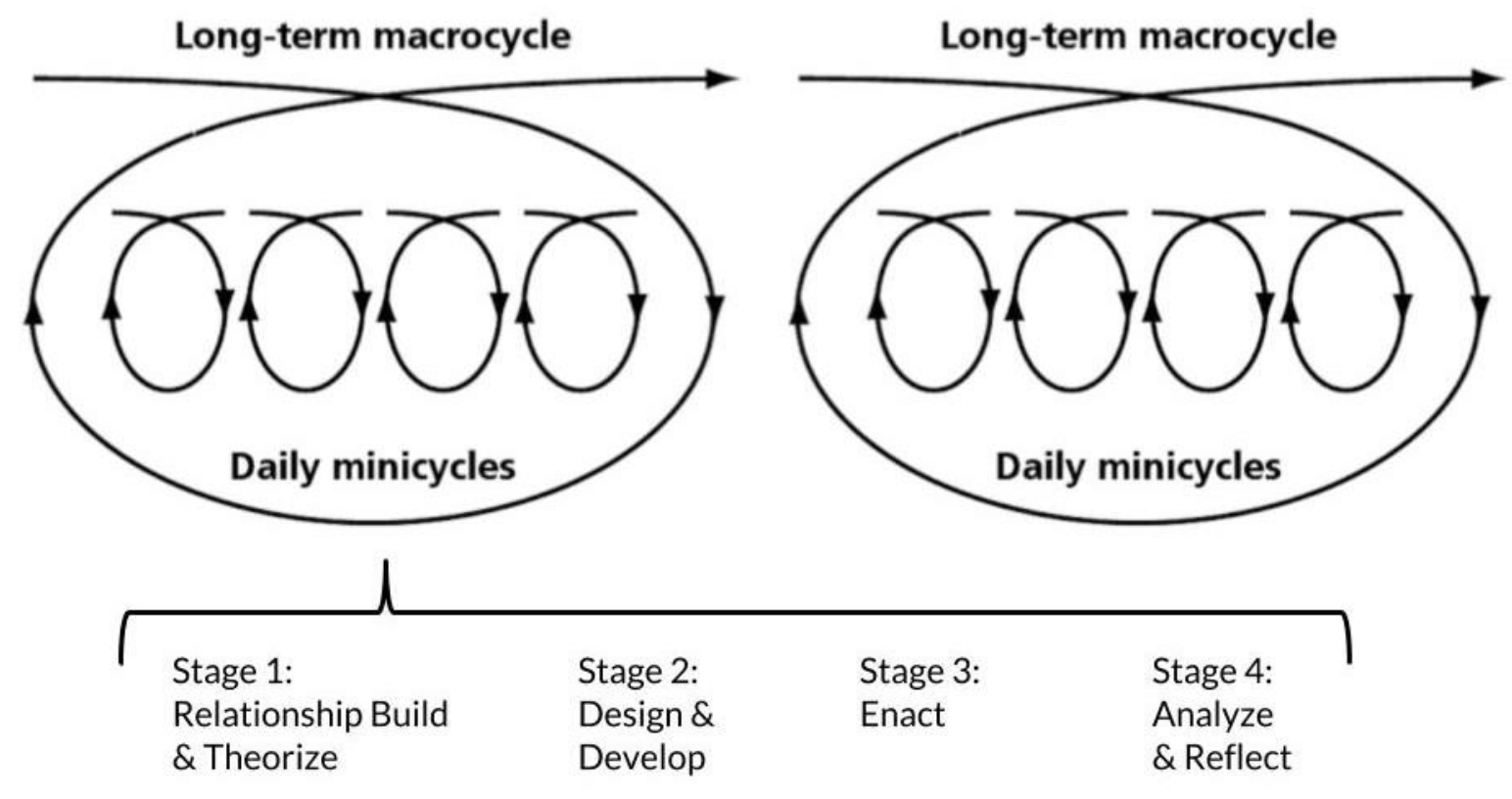

(adapted from Gravemeijer \& Cobb, 2006)

Figure 1. Stages of Co-Design with Macro and Micro Cycles

Co-design requires that we, as researchers, are full and meaningful participants as codesigners in the research and implementation process (Bang \& Vossoughi, 2016; Gutiérrez \& Jurow, 2016). Thus, the expansion of identities and transforming of relationships includes our relationships with each other, communities, and institutions. Engaging as co-designers opens new ways of being and doing in the research process, including question generation, data analysis, and writing for publication. In this project we bring our positionalities as women of color, with our own identities, knowledges, and histories into the design process as essential components that constitute collaborative work and collective learning.

\section{Illustration of Co-Design in the Family Leadership Design Collaborative}

In order to illustrate solidarity-driven co-design, we use examples from a participatory design research project: The Family Leadership Design Collaborative (FLDC). The FLDC seeks to cultivate, enact, and sustain community wellbeing and educational justice through co-design with communities, families, and educational systems (Ishimaru \& Bang, 2016). We are a national, interdisciplinary collaborative of family members, community leaders, educators, and researchers whose work centers racial equity in family engagement. Starting in 2015, we began the FLDC through our personal and professional networks by inviting scholars, practitioners, and community leaders in fields such as family engagement, community organizing, education leadership, and design research to join our leadership team and guide the collective work of the collaborative. Through an initial convening with our leadership team we expanded our network to invite additional members in order to articulate a shared vision of equitable family engagement and co-design a national research and practice agenda. The majority of our members are from communities of color spanning 16 states as well as the District of Columbia (though a number are focused nationally) and bring a broad range of individual and collective community, professional, and research expertise. As a collaborative we have convened several times over the 
past few years to build strategic bridges between research and practice, disciplinary fields, and racial/ethnic communities.

As the FLDC, our vision is to design, enact, and refine new theories and manifestations of community wellbeing and educational justice predicated on a) whole, healthy children in culturally thriving families and communities; b) relational, communal, and collective approaches to change-making; and c) just institutions, policy, and practices. Concretely, this meant the development of a new research-practice agenda (Ishimaru \& Bang, 2016) and a series of design principles that inform not only the changes we seek to cultivate in the communities we partner with, but in the partnerships themselves. Further, we engaged in solidarity-driven co-design in 10 local sites with geographically, linguistically, and racially diverse families and communities to develop new theories and practices that support transformative possibilities. These sites were self-selected from researchers, practitioners, and community members in our collaborative.

Community design circles became a co-design practice across local contexts aimed at cultivating and enacting new relationships and theories that centered on nondominant communities' own definitions of wellbeing and educational justice. Community design circles were a first step toward imagining, designing and enacting macro-level change that begins with and centers families and communities. We had originally intended to conduct focus groups as a way to surface community definitions of wellbeing and justice and to identify leverage points for transformative change; however, our national collaborative pushed us think about other research practices that would better align with our collective stances and commitments and could potentially cultivate family and community leadership in their own changemaking. As such, community design circles emerged as an ideal practice to engage in our co-design process with local communities.

Building from Indigenous methodologies (e.g., Kovach, 2010; Smith, 2013) and community-based design research (Bang et al., 2010) we engaged in community design circles as a practice of co-design. Community design circles are in-depth, reciprocal working groups that aim to engage stories, experiences, and expertise within our communities in order to catalyze action within a particular context. In previous community-based design research, design circles were an innovation aimed at incorporating Indigenous families and communities in the design and implementation of a series of decolonial and resurgence projects (Bang et al., 2010). Community design circles were a culturally sustaining way to engage Indigenous elders and community members, beyond hierarchically driven decision-making or extractive research practices.

The context, participants, and object of co-design in our project differed by each site (see discussion below); however, the dimensions and design circle process were a common approach across these places. Each site engaged in three-to-four initial community design circles lasting one-to-three hours with a range of co-design participants (co-designers) including researchers, educators, school administrators, community organizations, and families. These design circles were facilitated by members of our collaborative who had relationships with the communities in which they were designing (e.g., superintendents, directors of community organizations, university researchers, etc.). We refer to these facilitators (a subset of co-designers at each site) as the co-design leadership team throughout the remainder of this paper.

A key feature of our community design circles was that many of our sites brought together families and members of different racial and linguistic communities (e.g., Latinx and African American families), or people who held differential roles with regards to schools (e.g., parents and principals) as co-designers. Local co-design leadership invited participants to join 
design circles based on their context and desired goal. For example, co-design leaders from the American Indian Center and North American urban indigenous communities in Chicago hoped to create a vision of global indigeneity, so they intentionally reached out to community leaders from Chicago-based Pacific Islander and Latin American indigenous communities to participate to form new relationships. In Southfield, Michigan, design circles deliberately brought parents and principals together to hear each others' stories and break down traditional hierarchical barriers between families and schools. In all of our sites, working across and with differences was an intentional effort to build and sustain solidarity in our design process.

Figure 2 represents the microcycles of co-design that we utilized in each of our 10 sites. These design circles made up the first stage of a larger macrocycle of a co-design process: Stage 1 , relationship building and theorizing. As we were focused on developing new relationships and theories from nondominant families and communities, we elaborate a bit here on our process of solidarity-driven co-design that allowed us to surface conceptually new territory and intervene in racialized or taken-for-granted scripts (Pushor, 2010 \& 2012; Ishimaru \& Takahashi, 2017). In particular we want to highlight that we 1) allowed time for these theories and relationships to emerge over the course of three to four sessions; and 2) carefully reviewed transcripts, audio, and video of previous design circles to make informed decisions about how to structure and facilitate subsequent design circles.

We (core investigative team and authors) and co-design leaders at each site began by mapping out the trajectory of the circles, recruitment, and potential facilitation strategies. Codesign leaders then facilitated their design circles, each of which constituted a 1.5-to-3-hour conversation and activities with local participants (examples in the next section). These circles were audio/video recorded and transcribed. Between design circles, site-based co-design leadership and core investigators reviewed transcripts from the previous design circle and identified conceptual themes and how participants and co-design leaders were interacting, particularly relative to racialized or taken-for-granted scripts (relational dynamics). In other words, we asked what was emerging and how. This preliminary analysis allowed us to make data-informed decisions about how to intervene in potentially problematic relationships or narratives. For example, upon revisiting transcripts from their previous conversation, co-design leaders in one context recognized the need to engage participants in questioning the unspoken authority designated to the white co-design leader (over the leader of color) in order to reimagine new ways of interacting with each other. Lastly, though it is beyond the scope of this paper, we (core investigative team) conducted qualitative and quantitative analyses of these design circles. Then, through collective sensemaking of the synthesized data with our co-design leaders, we produced summaries of the theories of change and key concepts to sustain and propel the future work of these communities and sought to contribute new insights to participatory processes in pursuit of educational justice. 


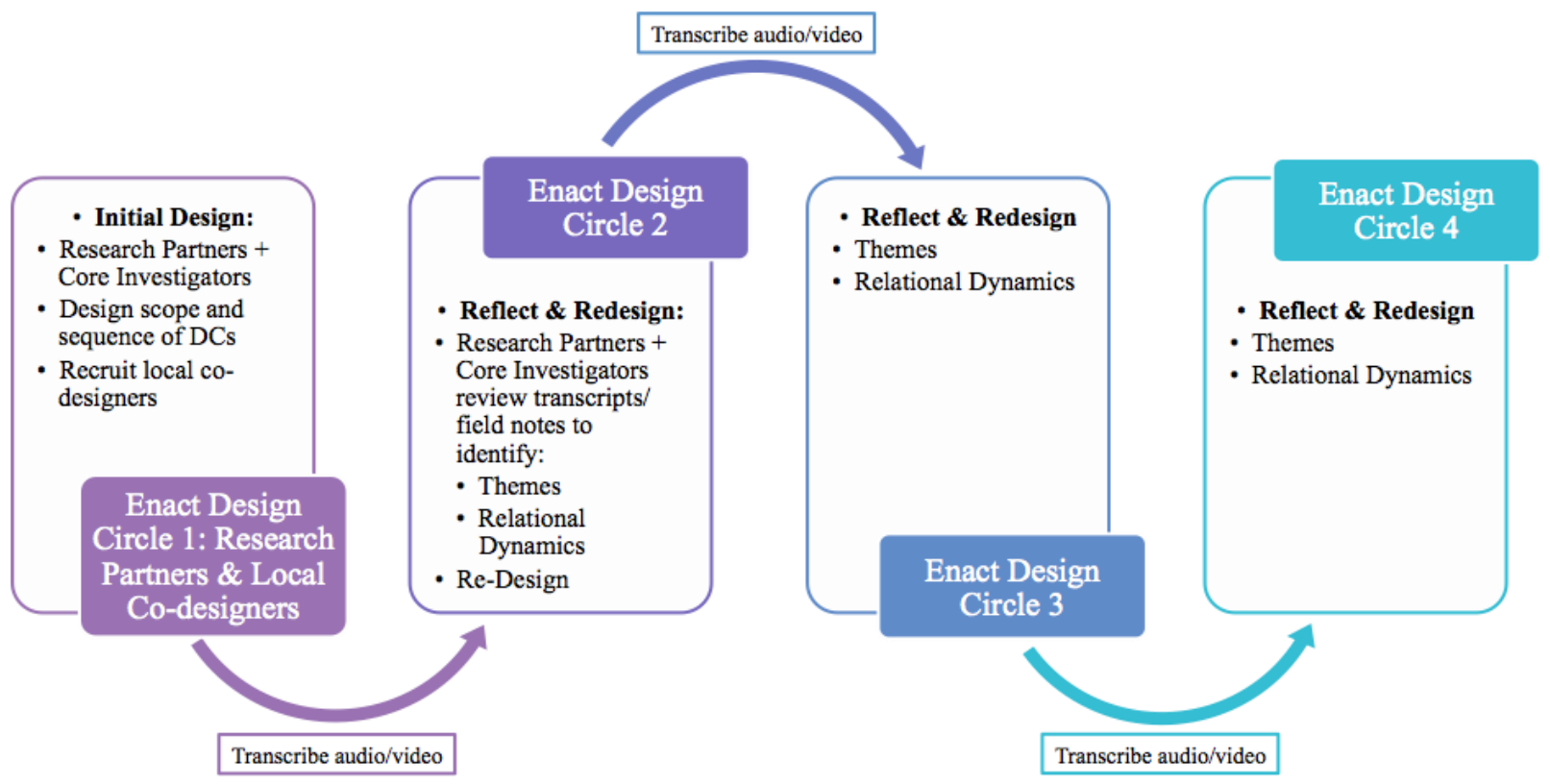

Figure 2. Community Design Circles as an Initial Stage of Co-Design

\section{Illustrating Foundational Dimensions of Co-Design through Community Design Circles}

Through the collective and iterative process outlined above, three dimensions of codesign are foundational to our solidarity-driven process: a) building from family definitions of wellbeing and justice; b) disrupting normative, asymmetrical power dynamics; and c) building capacity for social dreaming and changemaking. We proposed that these three dimensions might cultivate transformative theories of change and solidarity relationships responsive to local communities. For the purpose of this paper, we describe these three dimensions as distinct; however, we see these dimensions as co-constituting and mutually informing one another. In the next section we aim to give shape to these three dimensions through illustrative examples from community design circles in three sites: Chicago, IL, Los Angeles, CA, and Salt Lake City, UT. We begin by framing the context, beginning design objectives of each site, and the co-designers engaged through this process. We then delve into each dimension with examples from these sites.

\section{Context of Sites}

Site 1: Building Global Indigeneity, Chicago, IL. Partnering with the (Native Hawai'ian) Aloha Center, the American Indian Center, and Native American Support Program at the University of Illinois, Chicago, co-designers aimed to build solidarities across multiple Indigenous communities toward an understanding of global indigeneity. Over the course of four community design circles, parents, community leaders, and researchers engaged as co-designers to explore the design question "How can we build solidarities across our different Indigenous communities?" These co-designers took up this question in many ways that included intergenerational learning and changemaking, recognizing historical oppression and Indigenous activism, and supporting communities and families in their healing and renewal of cultural practices in ways that do not collapse diversity or complexity. 
There were between 7-8 co-designers present for each design circle. These co-designers included Indigenous community members whose homelands extend through the continental southwest and midwest of the US, Canada, and the Pacific Islands. These design circles were cofacilitated by community members and a non-Indigenous faculty researcher at Northwestern University. An Indigenous community member/research faculty from Northwestern cofacilitated the first design circle. A member of our research team joined the final design circle, who is also from an Indigenous community and was director of the American Indian Center for nearly 15 years.

Site 2: Humanizing Parent-Teacher Interactions, Los Angeles, CA. The community advocacy organization CADRE in South Los Angeles, California, brought together African American and Latinx families and organizational staff to build on their decades of work disrupting the school-to-prison pipeline to envision how moment-to-moment interactions with teachers could unfold in more humanizing and transformative ways. These co-designers engaged the question of "How can we redefine parent relationships with teachers towards wellbeing and justice for South L.A. students of color?" Within these design circles, co-designers envisioned and embodied the types of relationships they hoped to see predicated on mutual trust, respect, and understanding. Through the development of new scripts for teachers and families, CADRE co-designers sought to enact systemic transformation through everyday forms of justice.

Each community design circle had between 10 and 15 designers present. Co-designers included the executive director of the organization, CADRE staff members, and parent leaders who had been involved with the organization from 6-15 years and were considered "veteran core parents." Staff and faculty were primarily Latinx and African American. Also present were a Latinx faculty researcher from the University of California, L.A. A member of our core investigative team joined the final design circle.

Site 3. Re-imagining School Community Councils, West Salt Lake City, UT. With the University of Utah, University Neighborhood Partners, Salt Lake City Schools, and the Community Advocacy Network (CAN), this set of design circles brought Latinx families, community leaders, and school and district staff together to re-envision the purpose and function of an existing school-based resource and decision-making body, School Community Councils (SCCs), to better serve community needs. Co-designers took up the design challenge of "How can we re-design SCCs to equitably and authentically engage families, particularly Spanishspeaking Latinx families, in site-based decision-making?"

Co-designers included families, educators, administrators, and community members. West Salt Lake City has a large Latinx immigrant community, and as such, co-design leadership endeavored to create a space for monolingual Spanish-speaking and bilingual family and community members to be able to participate and design in generative ways. This included facilitation in both English and Spanish and opportunities for same-language discussion and cross-language discussion with translation throughout the four design circles. Circles were primarily facilitated by a Latino faculty researcher from the University of Utah in both Spanish and English.

\section{Three Dimensions of Co-design, Illustrated}

Building from and with family definitions of wellbeing and justice. We began design circles by surfacing family stories and histories related to community wellbeing and educational justice. In doing so, we aimed to frame families as experts in their own communities, whose perspectives matter for shaping decisions that affect their lives. This was an explicit refusal of normative family engagement practices that frame families as lacking in appropriate skills or 
knowledge, or that begin with a prescribed set of goals and agenda (Warren et al., 2009).

We explicitly named family stories as the grounds for expansive theory building. We see this is as a distinguishing characteristic of co-design: that we are not only looking for families to tell their stories, but also fostering critical reflection across shared or distinct experiences and histories with educational institutions, what we earlier referred to as designing with critical historicity. We encouraged stories of both inequity and thriving in order to recognize the dynamic and powerful histories of our communities. In other words, through our co-design we asked families to envision possible futures that build upon their priorities and values in ways that address historical and ongoing inequities. These stories and emerging theories of change became our community definitions of wellbeing and justice that were multiple and layered.

Each site took up this practice of engaging family and community stories in ways that supported their collective dreaming of wellbeing and educational justice. In the Chicago-Global Indigeneity design circles, co-design leadership used a "river of life" activity to visually capture co-designers' narratives and ideas over the life course of the design circles. The broad goals of the river of life activity were threefold: a) to engage community members in sharing stories and identifying shared experiences and systemic inequities; b) to collectively reflect the current educational challenges and opportunities; and c) to imagine future pathways and creating collective actions for community and family well-being.

Concretely, the co-design leadership team prepared a large chart paper with the drawing of a river across the length of the papers and then taped it to the wall at eye-level. This river was divided into three sections: "Past," "Present," and "Future." In the first design circle, leadership gave co-designers large markers and asked them to write down on the chart paper what they believed were "needs, challenges, and opportunities" when they thought about their "educational landscape," which included "family, communities, schools, out-of-school settings, and educational justice." Co-design leadership team members, in addition to facilitating these design circles, were also participants in the design circle process. As such, they also contributed to the river of life and to the discussions afterwards.

Co-designers (including the leadership team) used sentences, phrases, drawings, or key words to describe their ideas and stories, then discussed what they wrote in this section of the river, sharing personal narratives to contextualize what they wrote and linking these experiences to broader systemic narratives of settler-colonialism (e.g., "historical trauma," "illegal overthrow of Native Hawaiian Kingdom by U.S. Govt") and Indigenous resurgence (e.g., "healing," "extended families as teachers," "recognizing rights"). For instance, one participant shared how her difficult experiences and relationship with her mother has shaped how she now raises her own daughter in hopes of avoiding the same experiences and to forge a new path. This sparked a collective conversation around the need to honor the past in order to build "trauma-free" futures. Co-designers repeated this process for past and future parts of the river to see the interwoven connections across time, space, and communities (Figure 3). The river of life visual was brought back at each subsequent community design circle as a way to orient new members and re-orient returning co-designers to the conversations and theories that were being cultivated around wellbeing and educational justice. 
The river and its pathway through time and space became a powerful metaphor and visual anchor for holding multiple stories, theories of change, and experiences. As one research partner, Cynthia, narrated in the first design circle, "[L]ike all rivers, there's different curves to them, there's also different tributaries that go into the river. There's a beginning to a river, there's a middle, and there's an end. Then there's also - maybe there's not even an end and that goes into different areas, keeps growing."

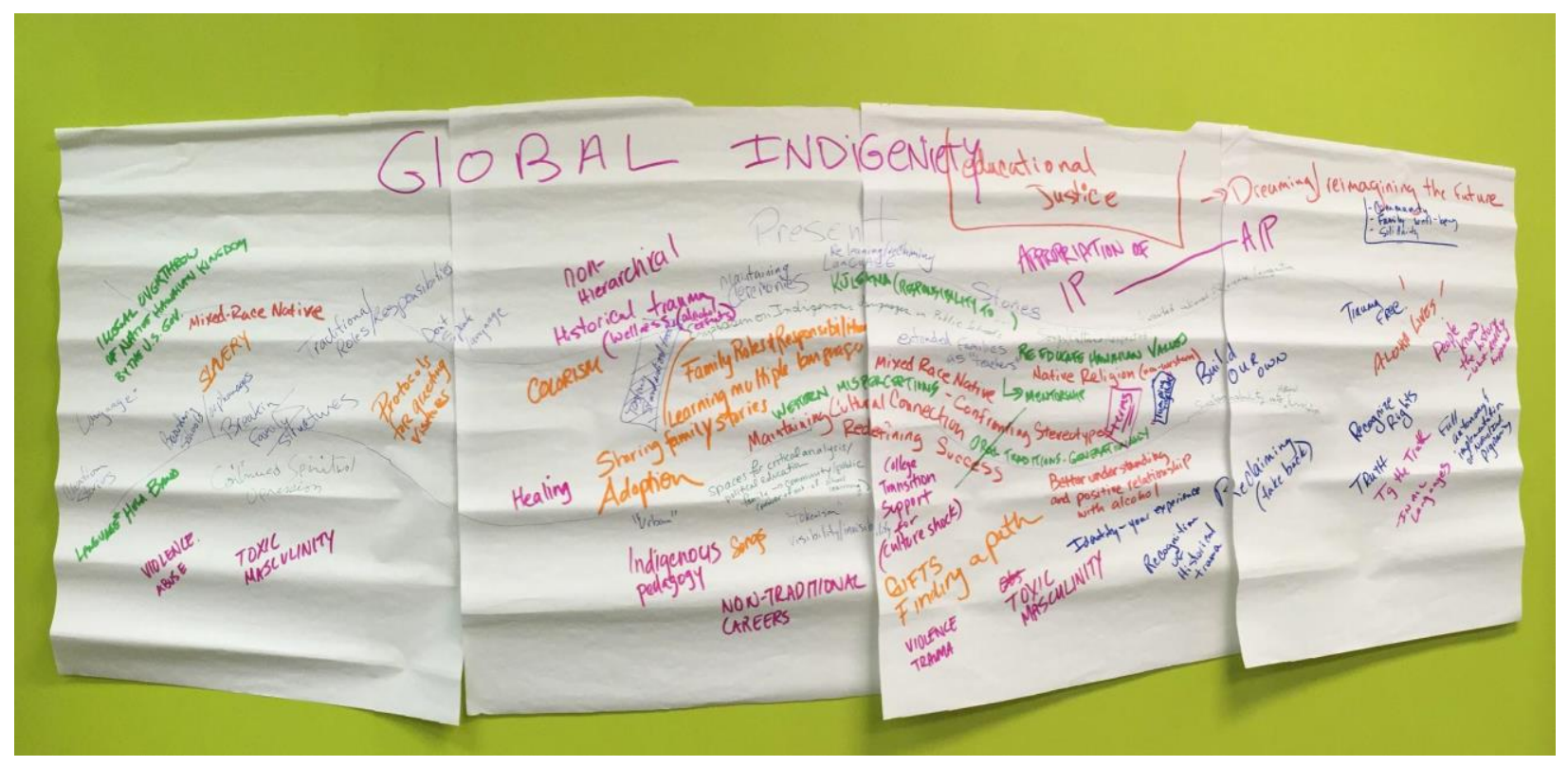

Figure 3. Photograph of River of Life Artifact from Chicago Design

In her work on stories as theories, Jo-ann Archibald (2008) reminds us that "Understanding and insights also result from lived experiences and critical reflections on those experiences. Many Aboriginal people have said that, in order to understand ourselves and our situation today, we must know where we come from and know what has influenced us" (p. 377). In this particular set of design circles, the river of life activity was a practice of co-design that enabled individuals to share their lived experiences - and those of their families and communities - and made space for critical reflection and collective designing. In other words, it laid the foundations for solidarity-driven design that was accountable to collective visions of wellbeing and justice, rather than being driven by individual agendas or token voices. Further, by simultaneously holding past, present, and future in the visual field, it endeavored to "both dream and contribute to birthing resurgences and Indigenous futures - an elsewhere to the current settler-colonial forms and systems of education - as well as to account for the here-and-now enclosures" (Bang et al., 2018, p. 3).

Disrupting normative power dynamics. The ways in which we enact our partnerships are as critical to justice and wellbeing as our conceptions and implementation of change. Design circles served as an important space to critically examine our relationships with each other and put forth new visions and practices for the relationships we wished to see in our broader communities. This included identifying, examining, and disrupting normative power relations and narratives that often emerge when working within heterogeneous groups.

Community design circles worked to disrupt normative dynamics through a variety of practices that would encourage participants to take each other's perspectives, challenge 
oppositional or transactional roles, and cultivate shared vulnerability. In Los Angeles, CADRE co-designers participated in role-playing and collective reflection with the intention of reimagining parent-teacher conversations and interactions. Although CADRE had been successful in passing school discipline policies that aimed to disrupt the school-to-prison pipeline, the fundamental relationships and interactions between families and teachers in schools continued to reflect racist, dehumanizing ideologies entrenched in inequitable power dynamics. In the original conceptualization of the design circles, we had wanted to invite teachers into these spaces to cultivate solidarity between families and educators; however, after the first design circle where families shared their ongoing negative interactions with teachers, CADRE leadership decided that putting families into such power-laden and potentially confrontational situations without having first designed generative ways into these conversations could lead to re-traumatization.

Role playing, then, was taken up as a practice for re-imagining how those conversations could go and rehearsing the kinds of changes families wished to see in their relationships with teachers. One of our co-design leaders, Maisie, framed these one-on-one conversations as key moments for intervention that could lead to systemic change. In the second design circle, she said:

CADRE believes that parents can actually interrupt the patterns of these conversations that often take place. So, we have the option to design what that interruption is but also, to have an interruption that shows the system, the teachers, the kind of relationship we want to have.... Teachers unfortunately are not rewarded for getting along with parents... and so, [they are not] seeing this gap in the system. And the system is not going to change itself. We are going to have to show it, the ways that it could change,... and I just want to paint a picture. Imagine if, when we get to the end and we have ways and we discover ways of re-framing it, the conversation. Imagine lots of parents being able to do it. And all these different moments in which they might be engaging schools. And maybe one day, teachers will actually learn from parents. Like really learn. Not get advice but learn.

In this quote, we see that imagining systemic change was an important goal of these community design circles and made visible possibilities for other ways of being and interacting that would be humanizing for families and for teachers. Role-playing, then, was a vehicle for collective imagining and changemaking.

Role-playing in this context entailed parents assuming roles of teachers and of parents and then acting out scenarios drawn from the lived experiences they had had with educators in school settings. Parents, in pairs and triads, were given time to reimagine a scenario in which they typically engage with a teacher (especially around problems or conflicts), rehearse their skit, and then perform in front of the group. CADRE staff helped families create and rehearse their skits and offered feedback. Performances in Spanish were translated into English and vice versa. After each performance, Maisie facilitated a critical reflection that was intended to name specific interactions that are well-worn dynamics and identify what might be potentially new ways of interacting. An important aspect of this reflective work was to tie these moment-to-moment interactions to broader systemic dynamics.

Similarly, Salt Lake City design circles sought to cultivate new relations between schools and communities in order to address barriers to family engagement in School Community Councils (SCC). A primary aim of the design circles was to envision new structures and practices for SCCs that would embody true democratic decision-making and authentic 
collaboration between schools and families, particularly immigrant, Spanish-speaking families who felt most excluded. While Los Angeles co-designers focused on developing community capacity for imagining and enacting new humanizing relationships with educators, the co-design leadership team in Salt Lake City aimed to foster these relationships in the design space itself by bringing educators and community members together in the design circles to envision and begin to enact a different system of shared governance. In other words, they sought to model a way of interacting with one another in their design circles that mirrored the ways equitable partnerships could be enacted in the SCCs. Recognizing the history of many school-community partnerships and research-practice partnerships that have left communities outside of key decision-making spaces, co-design leadership team in Salt Lake City were diligent in their co-design to cultivate an equitable space for everyone in the process. Many of these practices were designed prior to the first design circle and included such practices as ensuring translation into English and Spanish, recruitment of individuals who were interested in supporting equitable school-family partnerships, and careful design of activities meant to create shared understanding of SCCs for re-design (López et al., 2017). They write:

From the beginning, we recognized that our work was being carried out within a context of long running institutionalized inequity. Each of our choices leading up to the design circles was made to at least slightly mitigate this inequity by establishing the space as one for educator and parent voice, as well as for all involved [including researchers] to take ownership over the process (López et al., 2017, p. 23).

In addition to these "pre-design" strategies, some of the practices and activities that took place in the design circles were co-designed in the interim between design circles as leadership team members and our core investigative team (primary investigators and research assistants) reviewed transcripts and field notes to identify moments for possible intervention (López et al., 2017). For instance, in reading the transcript from the first session, the lead facilitator realized he and a few others may have been dominating the conversation; in the next session, they not only changed the prompts and plan to include more voices, he also explicitly modeled his reflections and the shift in his facilitation to invite others to reflect on their own participation. Thus, an iterative process of intentional design and re-design of our research activities was key to supporting both different relationships and different theories of wellbeing and justice. The Los Angeles and Salt Lake City design circles highlighted existing policies and structures in place to promote school-community partnerships and family decision-making; however, families, community members, and educators in these contexts were frustrated by routine processes that reinforced hierarchical power and static normative roles that replicated unjust relational activities. Thus, across these contexts, equity-oriented policies and structures did not inherently or automatically foster solidarity relations between families and schools. Rather, solidaritydriven co-design methodologies seek to transform systems by attending to - and intervening inthe moment-to-moment processes that can reinforce normative power and role dynamics as well as constrain possible solutions.

Cultivating spaces for social dreaming and changemaking. In our final dimension, we examine how cultivating spaces for social dreaming and changemaking generated new theories, knowledge products, and relationships that were attentive to the needs of community while also contributing to our model of transformative family leadership. In other words, here we describe how co-designers across these diverse contexts engaged in their own "how can" questions to collectively imagine future possibilities that addressed, but were not constrained by, historical and lived inequities. Importantly, we explicitly designed for new products, tools, processes, 
practices, and relations all as valid "outcomes" of our design circles toward collective transformative agency and community self-determination. For example, in our draft community design circle protocols that were sent to all sites as a launch pad for their own site-based design, we (core investigative team) outlined two potential options for "products" that could result from the community design circles: the co-design of a strategic action or the co-design of a particular product or tool. By offering different options, we wanted to signal that there were a wide variety of outcomes from co-design that could impact wellbeing and educational justice.

Additionally, by clearly articulating the investigative team's research protocols and including our co-design leadership team in the process of data collection, analysis, and dissemination (e.g., presentations at conferences, written products, etc.) our goal was to validate the learning process - that is, what we learned by designing, enacting, and refining our interventions - as a consequential outcome of community design circles. This was particularly important given the different trajectories for social dreaming and changemaking we anticipated, since some of our design circles brought together people who had never met (e.g., Salt Lake City), knew each other but had never collaborated on a shared project (e.g., Chicago), or had been working intimately for over six years (e.g., Los Angeles). Thus, in the examples below, we elucidate how engaging in social dreaming and changemaking promoted the co-design of family, educator, and researcher tools and products in Salt Lake City and the launch of a new collaboration of community members and organizations in Chicago.

In Salt Lake City, several key barriers to equitable school collaborations were identified in the first two design circles and were addressed in the third design circle where co-designers were tasked with envisioning their ideal School Community Council. Specifically, they aimed to transform SCCs from a compliance mechanism (i.e., families serving as a "rubber stamp" to passively sign off on school priorities) to a process of community ownership and decisionmaking. During this third design circle, our research partner, Gerardo, began by sharing quotes from transcripts of the first two design circles that exemplified key emerging themes or barriers to equitable engagement in SCCs. After co-designers had time to reflect on these quotes, they were gathered into small mixed groups of educators, administrators, and families and given chart paper and markers in order to draw their ideal SCC (Figure 4). Similar to the river of life activity in Chicago, pairing these quotes from previous design circles with opportunities for social dreaming in the third design circle was an intentional practice to connect co-designers' ideas across time and space. In this third design circle, our co-design leadership team noted a change from previous design circles where co-designers had fewer opportunities for active participation and collective visioning of future possibilities. They reflected: 
[W] saw a qualitative shift toward equitable collaboration in the space. We were able to dispense with information sharing, and move on to collective imagination, which sparked far-ranging conversations among mixed groups of parents and educators.... The products that emerged from these small group discussions were quite powerful. Participants not only demonstrated that they had thought deeply about the work that we had done up to that point, but their final products truly represented the collective voice of everyone involved (López, et al., 2017, p. 24).

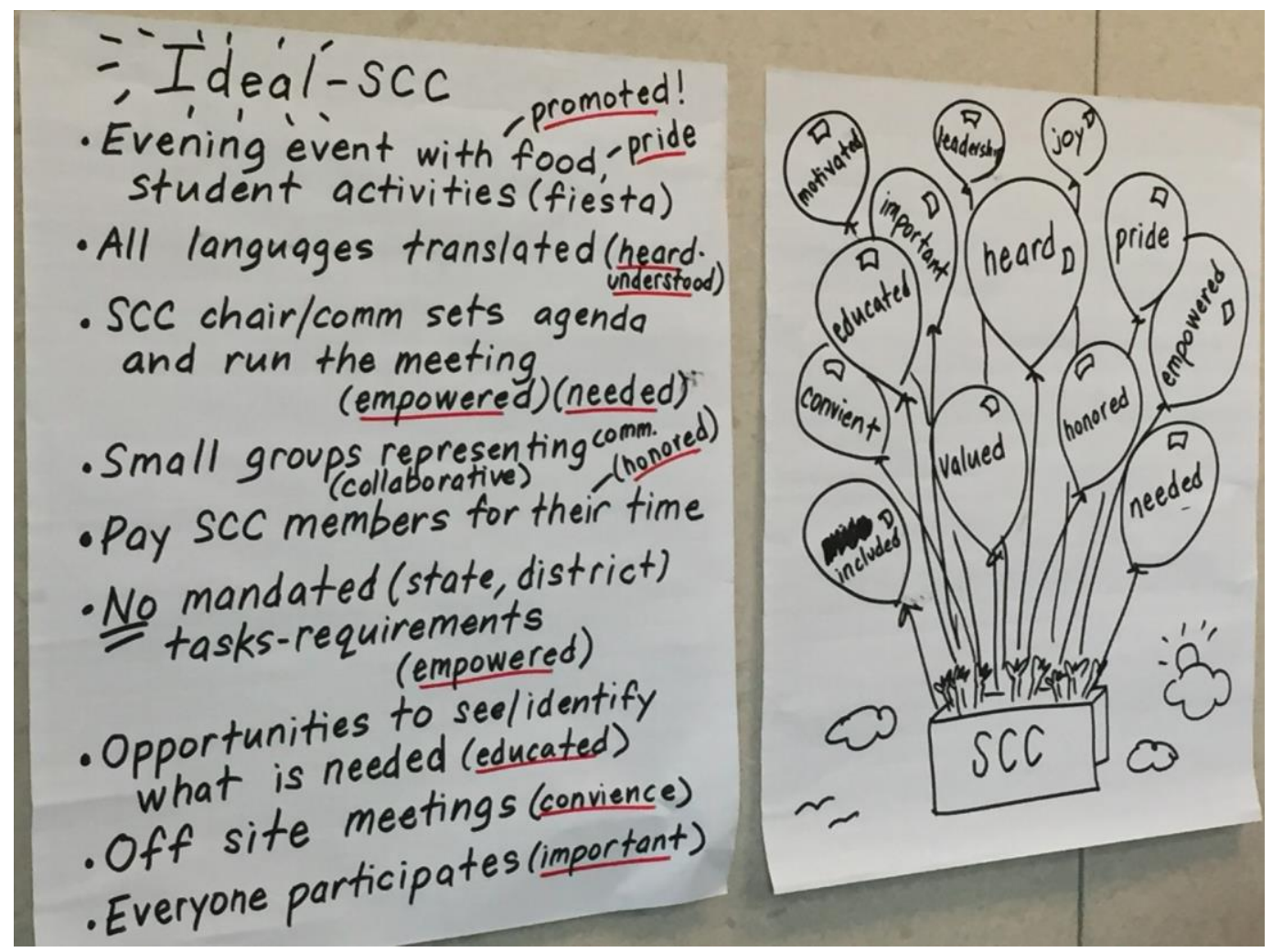

Figure 4. Example Drawing of an Ideal SCC

Thus a critical aspect of co-design was that the products that culminated from these community design circles reflected the shared vision that had been building over the life course of the project. In addition to these initial sketches, a fourth design circle in Salt Lake City was convened to concretize some of the themes and actions identified in the third design circle. Several key products from this design circle included a report for administrators and educators about how to cultivate equitable school-community partnerships and make SCCs viable spaces for authentic decision-making and ownership of the process. Additionally, a subsequent set of meetings with participating parents and a local artist resulted in a family booklet that depicts some of the key functions and processes of SCCs in the style of a comic strip. Further, the relationships that were cultivated during the community design circles have become the foundation for launching a new phase of co-design work to expand the critical role of families and communities in schools.

While Salt Lake City co-designers focused on transforming an existing structure within 
schools to be more equitable, Chicago co-designers endeavored to bring Indigenous community members together for the first time to begin the process of identifying what could or should be the goal of their collaborative. Working completely outside of schools, this group of individuals sought to generate a collective understanding of the issues facing their Indigenous communities and the resources, knowledges, and practices that could be leveraged to address these issues. A core component of this social dreaming process was to identify and (re)create the conditions in which changemaking could unfold in their different community contexts. Thus, for the Chicago co-designers, educational justice was less about school-based reform and more about renewing Indigenous practices for socialization, identity development, and health and wellbeing, particularly new practices for healing from historical trauma.

In this way, re-membering (Corntassel \& Scow, 2017) intergenerational and crosscommunity relations was a prominent theory of change that developed over the four Chicago design sessions. Co-designers narrated a need for creating intentional spaces to connect elders and youth in traditional practices, as well as spaces for youth to become "good elders." This included deep discussion about what qualities — such as care and wisdom-make a good elder and how young people can be raised into elders. This theory of change and the solidarity cultivated through the community design circle process are as much equitable outcomes of codesign as the tools and knowledge products that proliferate in the field.

\section{Conclusions}

In this piece, we propose community design circles within co-design methodology as an approach to collaborating in research with families, communities, educators, and researchers in equitable and responsible ways. Through iteration and refinement of our practices, we believe that design work can push the field of family engagement to consider new ways of studying and cultivating the conditions under which authentic and trusting partnerships can be built. Furthermore, we believe that as a solidarity-driven process, co-design has the potential to transform how we, as educational researchers, partner with families and schools to create and sustain just systems of education.

To illustrate how community design circles addressed three key co-design dimensions, we examined the co-design practices that were designed and implemented in three community design circles to: a) build from and with family definitions of wellbeing and educational justice; b) disrupt normative, asymmetrical dynamics; and c) build capacity for social dreaming and changemaking. Our examples illuminate how co-designers in diverse contexts with different aims of co-design integrated practices that attend to these dimensions in their design processes.

For Chicago, design circles engendered identification of barriers to wellbeing and educational justice and dreaming possible new futures through the River of Life activity. These circles sustained deep deliberation about core values and histories that connected diverse Indigenous communities. This group of co-designers began to build solidarity across their different communities as they sought to support each other in their individual and collective struggles to raise good elders and enact the kinds of just and healing relationships they hoped to see in future generations.

For the Los Angeles group, holding space to imagine and practice humanizing and healthy relationships with schools was a necessary first step in designing with and from family definitions of wellbeing and justice and was an intentional disruption of school-family and research-family dynamics that may inadvertently place families in harmful situations. The stories that families shared in this context were meant to build solidarity between African American and Latinx families who experienced similar frustrations and discriminations within schools, rather 
than telling stories for researchers or educators to "put their trauma on display."

In Salt Lake City, design circles served as a structure and process to collectively critique and re-design School Community Councils toward authentic family participation and decisionmaking in SCCs. These circles intentionally sought to build new relationships between Latinx families, educators, and researchers in the design circles as a model for the kinds of relationships they hoped to cultivate in SCCs and broader family-school relations. Further, taking the time to analyze interactions between the co-design leadership team and other co-design participants made visible normative power dynamics that were operating within the design circles and which ran counter to the vision of equitable partnership, as well as opened opportunities for participants to reshape their dynamics toward building solidarities.

And yet, even as we began with families and communities connecting their stories and theorizing about possible futures, we also anticipated that in our design circles we would likely slip into normative dynamics, such as principals enacting hierarchical power with families, or racialized narratives about what constitutes "good" or "bad" parenting (Ishimaru \& Takahashi, 2017). This is not to suggest that we (authors and co-designers) were not well-intentioned; however, even when researchers recognize group dynamics defaulting to normative scripts, we often do not know what to do when they arise. Conventional (i.e., positivist) research methods argue that intervening in such moments violates standards of distance and neutral objectivity. More community-engaged scholarship methods might work to be self-aware, transparent, and explicit about these dynamics but yet refrain from intervention, as it might threaten the boundaries of "researcher" and "community member."

In contrast, solidarity-driven co-design is premised on carefully attending to and recording interactions as they unfold in real time for the purpose of intervention. Concretely, this meant we looked to our data - in this case, transcripts of conversations and field notes of design circles - to identify patterns of normative discourse and dynamics to (re)design our practices. Often, we put these dynamics back in front of all the co-designers in the design circles as a way to make visible tensions arising in the design space and engender discussion and collective decision-making about them. Thus, we were able to design, try out, and learn from our interventions over time.

Although our representation of community design circles may appear straightforward in retrospect, we acknowledge that the process of collective learning, building solidarities, and changemaking is filled with challenges, uncertainties, and complexities. As researchers, solidarity-driven co-design requires vulnerability, reflective, and reflexive practice that may run counter to the ways we have been trained and socialized to undertake research. And as community leaders and educators, we are often expected to lay out the agenda and direct action towards pre-determined outcomes, rather than adjusting and facilitating toward evolving collective priorities and direction. Moreover, community design circles are a beginning. While we worked to build (and repair) relationships and open space for social dreaming, we did not expect three or four design circles to realize sustained and transformative change. As we work toward wellness and justice in the next phases of the Family Leadership Design Collaborative, we expect to continue to grapple with how to support our collective learning and move conversations beyond the design circles toward implementing, iterating, and enacting new practices and activity in the world.

These varied design circles also offer insights into the potential of solidarity-driven codesign to shift roles, relations, and conceptions of expertise between researchers and "the researched," beyond re-framing who has expertise. We engaged as co-designers to bring our full 
selves, including our histories, knowledges, and cultural practices, to the collaborative envisioning and designing of solutions to collectively-defined issues. As we work to transform the dynamics between educational systems and families, we also aspire to transform the processes by which we make decisions at all levels, including those within the Family Leadership Design Collaborative. As researchers, we experienced community design circles as a transformative process for our own collective learning and growth. Our iterative analysis of the design circles led to the development of a set of partnering commitments and the evolution of a solidarity-driven decision-making process that shaped how we moved into the next phase of codesign work with a subgroup of our community design circle sites. The dimensions outlined in this paper constitute the core project design principles that were informed by and evolved over the course of this project.

Collectively, as families, communities, educators, and researchers - in short, as knowers and doers in transforming education-we recognize that our interactions in research, the findings we produce, and the change we pursue are all powerfully intertwined. We posit that co-design processes and practices, such as community design circles, offer possibilities for engendering new theories of change and living the solidarities we seek to build, towards wellbeing and justice as defined by communities themselves.

Acknowledgements: The authors would like to express their appreciation to the W. K. Kellogg Foundation, the FLDC Leadership Team, UW research assistants Henedina Tavares and Mario Guerra, Dr. Jondou Chase Chen, the UW Institute for Science and Mathematics, and our research and community partners: Dr. Gerardo López, Dr. Paul Kuttner \& Alma Yanagui (University of Utah, University Neighborhood Partners, Community Advocacy Network, and Salt Lake City Schools); Maisie Chin (CADRE) and Dr. Lorena Guillén (UCLA); and Cynthia Soto, Dr. Shirin Vossoughi, Dr. Ananda Marin, Lanialoha Lee (Aloha Center Chicago), and the American Indian Center 


\section{References}

Anderson, G. L. (1998). Toward authentic participation: Deconstructing the discourses of participatory reforms in education. American Educational Research Journal, 35, 571603.

Anyon, J. (2009). Progressive social movements and educational equity. Educational Policy, $23,194-215$.

Archibald, J. A. (2008). An indigenous storywork methodology. In, J. G. Knowles \& A. L. Cole, (Eds.), Handbook of the arts in qualitative research: Perspectives, methodologies, examples, and issues (pp. 371-393). Thousand Oaks, California: Sage Publications, Inc.

Auerbach, S. (Ed.). (2012). School leadership for authentic family and community partnerships: Research perspectives for transforming practice. New York, NY: Routledge.

Auerbach, S. (2007). From moral supporters to struggling advocates: Reconceptualizing parent roles in education through the experience of working-class families of color. Urban Education, 42, 250-283.

Bang, M., Faber, L., Gurneau, J., Marin, A., \& Soto, C. (2016). Community-based design research: Learning across generations and strategic transformations of institutional relations toward axiological innovations. Mind, Culture, and Activity, 23, 28-41.

Bang, M., Medin, D., Washinawatok, K., \& Chapman, S. (2010). Innovations in culturally based science education through partnerships and community. In M. Khine \& I. Saleh (Eds.), New Science of Learning (pp. 569-592). New York, NY: Springer.

Bang, M., Marin, A., \& Medin, D. (2018). If Indigenous peoples stand with the sciences, will scientists stand with us? Daedalus, 147(2), 148-159.

Bang, M., Montaño Nolan, C., McDaid-Morgan, N. (2018). Indigenous family engagement: Strong families, strong nations. In E. McKinley \& L. Smith (Eds.), Handbook of Indigenous Education (pp. 1-22). Singapore: Springer.

Bang, M., \& Vossoughi, S. (2016). Participatory design research and educational justice: Studying learning and relations within social change making. Cognition \& Instruction, 34, 173-193.

Baquedano-López, P., Alexander, R. A., \& Hernández, S. J. (2013). Equity issues in parental and community involvement in schools: What teacher educators need to know. Review of Research in Education, 37(1), 149-182.

Bell, D. A., Jr. (1980). Brown v. Board of Education and the interest-convergence dilemma. Harvard Law Review, 93, 518-533.

Bell, P. (2004). On the theoretical breadth of design-based research in education. Educational Psychologist, 39, 243-253.

Bertrand, M., Durand, E. S., \& Gonzalez, T. (2017). "We're trying to take action": Transformative agency, role re-mediation, and the complexities of youth participatory action research. Equity \& Excellence in Education, 50, 142-154. 
Bolívar, J. M., \& Chrispeels, J. H. (2011). Enhancing parent leadership through building social and intellectual capital. American Educational Research Journal, 48, 4-38.

Booker, A., \& Goldman, S. (2016). Participatory design research as a practice for systemic repair: Doing hand-in-hand math research with families. Cognition and Instruction, 34, 222-235.

Booker, A. N., Vossoughi, S., \& Hooper, P. K. (2014). Tensions and possibilities for political work in the learning sciences. In Proceedings of the International Conference of

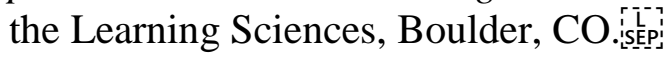

Brayboy, B. M. J. (2005). Toward a tribal critical race theory in education. The Urban Review, 37, 425-446.

Bryk, A. S., Sebring, P. B., Allensworth, E., Easton, J. Q., \& Luppescu, S. (2010). Organizing schools for improvement: Lessons from Chicago. Chicago, IL: University of Chicago Press.

Cammarota, J., \& Fine, M. (2008). Youth participatory action research: A pedagogy for transformational resistance. In J. Cammarota \& M. Fine (Eds.) Revolutionizing education: Youth participatory action research in motion (pp. 1-12). New York, NY: Routledge.

Coburn, C. E., \& Penuel, W. R. (2016). Research-practice partnerships in education: Outcomes, dynamics, and open questions. Educational Researcher, 45, 48-54.

Cole, M. (1998). Cultural psychology: A once and future discipline. Harvard University Press.

Corntassel, J., \& Scow, M. (2017). Everyday acts of resurgence: Indigenous approaches to everydayness in fatherhood. New Diversities, 17(1), 55.

Design-Based Research Collective. (2003). Design-based research: An emerging paradigm for educational inquiry. Educational Researcher, 32, 5-8.

Doucet, F. (2011). (Re) constructing home and school: Immigrant parents, agency, and the (un)desirability of bridging multiple worlds. Teachers College Record, 113, 2705-2738.

Dyrness, A. (2009). Cultural exclusion and critique in the era of good intentions: Using participatory research to transform parent roles in urban school reform. Social Justice, 36(4), 36-53.

Engeström, Y. (2004). New forms of learning in co-configuration work. Journal of Workplace Learning, 16(1/2), 11-21.

Epstein, J. L. (1992). School and family partnerships. In M. Alkin (Ed.), Encyclopedia of Educational Research (pp. 1139-1151). New York, NY: Macmillan.

Epstein, J. L. (1995). School/family/community partnerships: Caring for the children we share. Phi Delta Kappan, 76, 701-712.

Erickson, F. (1994). Where the action is: On collaborative action research in education. Bulletin of the Council for Research in Music Education, 123, 10-25. 
Espinoza, M. L. (2008). Humanization and social dreaming: A case study of changing social relations in a summer migrant educational program. (Doctoral Dissertation). Retrieved from ProQuest: 3302577.

Fernández, E., \& López, G. R. (2017). When parents behave badly: A critical policy analysis of parent involvement in schools. In M. D. Young \& S. Diem (Eds.), Critical Approaches to Education Policy Analysis (pp. 111-129). Switzerland: Springer.

Fine, M., Torre, M. E., Boudin, K., Bowen, I., Clark, J., Hylton, D., \& Upegui, D. (2003). Participatory action research: From within and beyond prison bars. In P. M. Camic, J. E. Rhodes, \& L. Yardley (Eds.), Qualitative research in psychology: Expanding perspectives in methodology and design (pp. 173-198). Washington, DC: American Psychological Association.

Fox, M., Mediratta, K., Ruglis, J., Stoudt, B., Shah, S., \& Fine, M. (2010). Critical youth engagement: Participatory action research and organizing. In L. R. Sherrod, J. TorneyPurta, \& C. A. Flanagan (Eds.), Handbook of research on civic engagement in youth (pp. 621-649). Hoboken, New Jersey: John Wiley \& Sons, Inc.

Gaztambide-Fernández, R. A. (2012). Decolonization and the pedagogy of solidarity. Decolonization: Indigeneity, Education \& Society, 1(1), 41-67.

Gutiérrez, K. D. (2008). Developing a sociocritical literacy in the third space. Reading Research Quarterly, 43, 148-164.

Gutiérrez, K. D., \& Jurow, A. S. (2016). Social design experiments: Toward equity by design. Journal of the Learning Sciences, 25, 565-598.

Gutiérrez, K. D., \& Vossoughi, S. (2010). Lifting off the ground to return anew: Mediated praxis, transformative learning, and social design experiments. Journal of Teacher Education, 61,100-117.

Gutiérrez, R. (2008). A “gap-gazing” fetish in mathematics education? Problematizing research on the achievement gap. Journal for Research in Mathematics Education, 39, 357-364.

Ishimaru, A. (2014). Rewriting the rules of engagement: Elaborating a model of district community collaboration. Harvard Educational Review, 84, 188-216.

Ishimaru, A. M. (2017). From family engagement to equitable collaboration. Educational Policy. https://doi.org/10.1177/0895904817691841

Ishimaru, A. M., \& Bang, M. (2016). Toward a transformative research and practice agenda for racial equity in family engagement [White paper]. Retrieved from the University of Washington: http://familydesigncollab.org/wp-content/uploads/2017/03/FLDCConvening-Report-Fin-033117.pdf

Ishimaru, A. M., Barajas-López, F., \& Bang, M. (2015). Centering family knowledge to develop children's empowered mathematics identities. Journal of Family Diversity in Education, 1(4), 1-21.

Ishimaru, A. M., \& Takahashi, S. (2017). Disrupting racialized institutional scripts: Toward parent-teacher transformative agency for educational justice. Peabody Journal of Education, 92, 343-362. 
Jimenez-Castellanos, O., \& Gonzalez, G. (2012). Understanding the impact of microaggressions on the engagement of undocumented Latino immigrant fathers: Debunking deficit thinking. Journal of Latinos and Education, 11, 204-217.

Kirmaci, M., Allexsaht-Snider, M., \& Buxton, C. A. (2018). Teachers' experiences with Spanish-speaking, bilingual families in a science learning context: Empowering teachers through home-school partnerships. Journal of Family Diversity in Education, 3(1), 23-47.

Kovach, M. (2010). Indigenous methodologies: Characteristics, conversations, and contexts. Toronto, Canada: University of Toronto Press.

Ladson-Billings, G., \& Tate, W. F. (1995). Toward a critical race theory of education. Teachers College Record, 97(1), 47.

Lareau, A., \& Horvat, E. M. N. (1999). Moments of social inclusion and exclusion: Race, class, and cultural capital in family-school relationships. Sociology of Education, 72, 3753.

Lawrence-Lightfoot, S. (2003). The essential conversation: What parents and teachers can learn from each other. New York, NY: Random House.

López, G. R., Yanagui, A., \& Kuttner, P. J. (2017, April). What does partnership taste like?: Reimagining family-school partnerships through participatory design research. Paper presented at the annual meeting of the American Educational Research Association (AERA), San Antonio, TX.

Madden, B., Higgins, M., \& Korteweg, L. (2013). "Role models can't just be on posters": $\mathrm{Re} / \mathrm{membering}$ barriers to Indigenous community engagement. Canadian Journal of Education, 36, 212-247.

Mapp, K. L., \& Kuttner, P. J. (2013). Partners in education: A dual capacity-building framework for family-school partnerships. Austin, TX: SEDL.

Mediratta, K., Shah, S., \& McAlister, S. (2009). Community organizing for stronger schools: Strategies and successes. Cambridge, MA: Harvard Education Press.

Mirra, N., Filipiak, D., \& Garcia, A. (2015). Revolutionizing inquiry in urban English classrooms: Pursuing voice and justice through youth participatory action research. English Journal, 105(2), 49.

Moll, L. C., Amanti, C., Neff, D., \& Gonzalez, N. (1992). Funds of knowledge for teaching: Using a qualitative approach to connect homes and classrooms. Theory Into Practice, 31 , 132-141.

Oakes, J., \& Rogers, J. (2006). Learning power: Organizing for education and justice. New York, NY: Teachers College Press.

Olivos, E. M. (2006). The power of parents: A critical perspective of bicultural parent involvement in public schools. New York, NY: Peter Lang Publishing, Inc.

Patel, L. (2015). Decolonizing educational research: From ownership to answerability. New York, NY: Routledge. 
Philip, T. M., Bang, M., \& Jackson, K. (2018). Articulating the "how," the "for what," the "for whom," and the "with whom" in concert: A call to broaden the benchmarks of our scholarship. Cognition \& Instruction, 36, 83-88.

Pushor, D. (2010). Are schools doing enough to learn about families? In M. Miller Marsh \& T. Turner-Vorbeck (Eds.) (Mis)understanding families: Learning from real families in our schools, (4-18). New York, NY: Teachers College Press.

Pushor, D. (2012). Tracing my research on parent engagement: Working to interrupt the story of school as protectorate. Action in Teacher Education, 34(5-6), 464-479.

Schutz, A. (2006). Home is a prison in the global city: The tragic failure of school-based community engagement strategies. Review of Educational Research, 76, 691-743.

Shirley, D. (1997). Community organizing for urban school reform. Austin, TX: University of Texas Press.

Smith, L. T. (2013). Decolonizing methodologies: Research and indigenous peoples. New York, NY: Zed Books Ltd.

Valdés, G. (1996). Con respeto: Bridging the distances between culturally diverse families and schools. New York, NY: Teachers College Press.

Valenzuela, A. (1999). Subtractive schooling: US-Mexican youth and the politics of caring. Albany, NY: SUNY Press.

Vakil, S., McKinney de Royston, M., Suad Nasir, N. I., \& Kirshner, B. (2016). Rethinking race and power in design-based research: Reflections from the field. Cognition and Instruction, 34, 194-209.

Warren, M. R. (2005). Communities and schools: A new view of urban education reform. Harvard Educational Review, 75, 133-173.

Warren, M. R., Calderón, J., Kupscznk, L. A., Squires, G., \& Su, C. (2018). Is collaborative, community-engaged scholarship more rigorous than traditional scholarship? On advocacy, bias, and social science research. Urban Education, 53, 445-472.

Warren, M. R., Hong, S., Rubin, C. L., \& Uy, P. S. (2009). Beyond the bake sale: A community- based relational approach to parent engagement in schools. Teachers College Record, 111, 2209-2254.

Warren, M. R., Mapp, K. L., \& the Community Organizing and School Reform Project (2011). A match on dry grass: Community organizing as a catalyst for school reform. Oxford, NY: Oxford University Press.

Warren, M. R., Park, S. O., \& Tieken, M. C. (2016). The formation of community-engaged scholars: A collaborative approach to doctoral training in education research. Harvard Educational Review, 86, 233-260.

Wilson, C. (2009). Parent involvement, African American mothers, and the politics of educational care. Equity \& Excellence in Education, 42, 379-394.

Zavala, M. (2016). Design, participation, and social change: What design in grassroots spaces can teach learning scientists. Cognition and Instruction, 34, 236-249. 
Community Design Circles: Co-designing Justice and Wellbeing

\section{Notes:}

${ }^{1}$ Following Gutiérrez (2008) and others, we use the term nondominant to highlight the historic dynamics and power relations that have marginalized communities, such as low-income, indigenous, immigrant/refugee, and other communities of color.

${ }^{2}$ We use the umbrella term family engagement here to refer to the myriad ways schools and families partner including family-school partnerships, parent involvement, etc. 